mẹ sử dụng thức ăn nhanh thường xuyên sẽ làm tăng tần suất sử dụng thức ăn nhanh của con cái $8,9 \%$ so với nhóm còn lại $(p=0,024)[6]$.

\section{KẾT LUÂN}

Kết quả nghiên cứu cho thấy tần suất sử dụng thức ăn nhanh ở mức độ thường xuyên là $42,4 \%$ và xác định được một số các yếu tố liên quan đến tần suất sử dụng thức ăn nhanh của học sinh như tần suất sử dụng bữa cơm gia đình, cha sử dụng thức ăn nhanh thường xuyên, me sử dụng thức ăn nhanh thường xuyên. Vì vậy, vể phía nhà trường nên tăng cường truyền thông giáo dục dinh dưỡng tại nhà trường để xây dựng thói quen ăn uống lành mạnh và hợp lý cho học sinh. Về phía gia đình và học sinh nên chủ động tìm hiểu về tác hại của thức ăn nhanh đồng thời hạn chế sử dụng thức ăn nhanh và cùng nhau sử dụng bữa cơm gia đình thường xuyên hơn.

\section{TÀI LIÊU THAM KHẢO}

1. Võ Thị Trúc Ly (2017) Tân suất sử dụng thức ăn nhanh và các yêu tố liên quan ở học sinh trường THCS Lý Tự Trọng, Quận Gò Vấp, TP.HCM năm 2017, Khóa luận tốt nghiệp Cử nhân Y tế công cộng

2. Nguyến Thanh Long Sơn (2018) Tỉ lệ thưa cân béo phì và các yếu tố liên quan của hoc sinh trường THPT Nguyễn Văn Cừ huyện Hóc Môn thành phố Hồ Chí Minh năm 2018, Khóa luận tốt nghiệp bác sĩ y học dự phòng

3. Sở Y tế Hà Nam (2021), 13 lý do nên từ chối thức ăn nhanh, https://syt.hanam.gov.vn/ Pages/13-ly-do-nen-tu-choi-thuc-an-nhanh.aspx, Truy cập ngày 17 tháng 08 năm 2021.

4. Amare Tariku, Solomon Mekonnen Abebe (2018) "Overweight/obesity among school aged children in Bahir Dar City: cross sectional study". Italian journal of pediatrics, 44, (1), 17.

5. Foad Alimoradi, Parisa Jandaghi, Adeleh Khodabakhshi, Maryam Javadi, Seyed Amir Hossein Zehni Moghadam (2017) "Breakfast and fast food eating behavior in relation to sociodemographic differences among school adolescents in Sanandaj Province, Iran". Electronic physician, 9 , (6), 4510.

6. Nitin Joseph, Maria Nelliyanil, et al (2015) "Fast food consumption pattern and its association with overweight among high school boys in Mangalore city of southern India". Journal of clinical and diagnostic research: JCDR, 9, (5), LC13.

7. Supa Pengpid, Karl Peltzer (2017) "The prevalence of underweight, overweight/obesity and their related lifestyle factors in Indonesia, 20142015". AIMS Public Health, 4, (6), 633.

8. Kathryn Walton, Nicholas J Horton, Sheryl L Rifas-Shiman, et al. (2018) "Exploring the role of family functioning in the association between frequency of family dinners and dietary intake among adolescents and young adults". JAMA network open, 1, (7), e185217-e185217.

\title{
ĐẶC ĐIỂM LÂM SÀNG VÀ CÂ̂N LÂM SÀNG CỦA BỆNH NHÂN LOẠN DƯỚNG NộI MÔ FUCHS
}

Phạm Thị Duyên ${ }^{1}$, Lê Xuân Cung²,
Dương Mai Nga ${ }^{2}$, Phạm Ngọc Đông ${ }^{2}$

\section{TÓM TẮT}

Mục tiêu: Nhận xét đặc điểm lâm sàng và cận lâm sàng của bệnh nhân loạn dưỡng nội mô Fuchs. Đối tượng và phương pháp: Nghiên cứu mô tả cắt ngang trên 40 mắt của 23 bệnh nhân trong 15 gia đỉnh được chẩn đoán loạn dưỡng nội mô Fuchs từ tháng 8/2020 đến tháng 7/2021. Kết quả: Có 10 bệnh nhân nam và 13 bệnh nhân nữ. Tuổi trung bình tại thời điểm phát hiện bệnh là $58,0 \pm 14,6$ tuổi. 100\% bệnh nhân bị bệnh cả 2 mắt. Có 6 bệnh nhân được phát hiện bệnh do đi khám tình cờ hoăc khám sàng lọc, 17 bệnh nhân đi khám vì có triệu chứng cớ năng như nhìn mờ hoặc chói, cộm, chảy nước mắt từng đợt.

${ }^{1}$ Bệnh Viện Mắt Thái Bình

${ }^{2}$ Bệnh viện Mắt Trung ương

Chịu trách nhiệm chính: Pham Thị Duyên

Email: Nhocphongvu@gmail.com.

Ngày nhận bài: 16.9.2021

Ngày phản biên khoa họ: 3.11.2021

Ngày duyệt bài: 18.11.2021
Khám lâm sàng thấy 25 mắt giác mạc còn trong, 15 mắt phù giác mạc. 33 mắt có hình ảnh guttae ở mặt sau giác mac, 7 mắt không quan sát được măt sau giác mac gồm 5 mắt giác mac phù, bong biểu mô nhiều và 2 mắt giác mạc đục, sẹo xơ ở giai đoạn cuối. Số lượng tế bào nội mô trung bình của 9 mắt đếm được nội mô là $2310 \pm 515$ tế bào $/ \mathrm{mm}^{2}$. Độ dày giác mạc trung bình của 40 mắt là $593,8 \pm 67,9 \mu m$. Kết luận: Bệnh loạn dưỡng nội mô Fuchs tại Việt Nam có các đắc điểm lầm sàng và cân lâm sàng điển hình như mô tả trong y văn. Chụp tế bào nội mô và đo độ dày giác mạc là hai xét nghiệm cận lậm sàng quan trọng trong chẩn đoán và theo dõi bệnh.

Tư khóa: Loạn dưỡng nội mô Fuchs.

\section{SUMMARY}

\section{CLINICAL AND SUBCLINICAL CHARACTERISTICS OF FUCHS}

ENDOTHELIAL CORNEAL DYSTROPHY

Objectives: Evaluation of the clinical and subclinical features of Fuchs endothelial corneal dystrophy. Subjectives and Method: A cross- 
sectional study. There were 23 patients (40 eyes) in 15 families, who had Fuchs endothelial corneal dystrophy, from August 2020 to July 2021. Results: There were 10 male patients and 13 female patients, with an average age of $58,0 \pm 14,6$ years. All patients were affected in both eyes by this disease. Six patients were discovered by chance during other examinations or while examining other members of affected families. There were 17 patients who experienced blurred vision or eye irritation. Clinical examination revealed that 25 eyes had clear corneas, 15 had corneal edema, and 33 had corneal guttae. Because of corneal edema and scarring, the posterior surface of 7 eyes could not be detected. Endothelial cell count was $2310 \pm 515$ cells $/ \mathrm{mm}^{2}$ on average. The average corneal thickness in 40 patients was $593,8 \pm 67,9 \mu \mathrm{m}$. Conclusion: Fuchs endothelial corneal dystrophy has typical clinical and subclinical features in Vietnam. Specular microscope and a corneal thickness measurement are important for following this disease.

Key words: Fuchs endothelial corneal dystrophy.

\section{I. ĐặT VẤN ĐỀ}

Loạn dưỡng nội mô Fuchs là hình thái hay gặp nhất trong 4 hình thái loạn dưỡng nội mô giác mạc, được mô tả lần đầu tiên bởi Ernst Fuchs năm $1910 .{ }^{1}$ Đây là bệnh lý chiếm tỉ lệ cao nhất trong số các nguyên nhân cần phải ghép giác mạc trên thế giới. ${ }^{2}$ Bệnh hiếm gặp, có đặc tính di truyền khá phức tạp và không đồng nhất với phần lớn các trường hợp không rõ đặc điểm di truyền và một số trường hợp được ghi nhận có đặc điểm di truyền trội nhiễm sắc thể thường. Có hai hình thái bệnh: hình thái xuất hiện sớm có thể biểu hiện trong 10 năm đầu đời và hình thái xuất hiện muộn ở tuổi 40 hoặc muộn hơn, trong đó hình thái xuất hiện muộn hay gặp hơn. Bệnh tiến triển ở hai mắt không cân xứng, đặc trưng bởi sự mất và biến đổi tế bào nội mô giác mạc với nhứng thay đổi về màng Descemet bao gồm sự tích tụ chất nền ngoại bào và hình thành các chất khu trú phía sau gọi là guttae. ớ giai đoạn đầu, giác mạc còn trong, bệnh nhân thường không có triệu chứng, các guttae hình thành ở trung tâm giác mạc và lan về phía ngoại vi, đây lồi bề mặt lớp nội mô và làm các tế bào nội mô bị bong ra. Sau đó, các guttae liên kết với nhau và lan về phía ngoại vi đồng thời có sự thay đổi hình dạng của các tế bào hình lục giác, bệnh nhân có biểu hiện nhìn mờ do phù nhu mố nhưng chưa có các triệu chứng kích thích mắt. Giai đoạn tiếp theo phù giác mạc tăng, xuất hiện các bọng biểu mô. Khi các bọng biểu mô vỡ sẽ gây ra trợt giác mạc. Bệnh nhân nhìn mờ nhiều, đau, kích thích, cộm chói, chảy nước mắt. Cuối cùng sẹo xơ xuất hiện giữa lớp biểu mô và màng Bowman làm hạn chế trợt biểu mô. Các triệu chứng kích thích mắt giảm nhưng thị lực giảm trâm trọng. ${ }^{3}$ Cần thận trọng khi chỉ định phẫu thuật để điêu trị bệnh đực thể thủy tinh cho bệnh nhân mắc loạn dưỡng nội mô Fuchs, do những mắt bị loạn dưỡng nội mô Fuchs có nguy cơ tiến triển thành bệnh giác mạc bọng nhanh hơn sau khi trải qua các phẫu thuật nội nhãn. ${ }^{4}$ Trên thực tế, nhiêu bệnh nhân loạn dưỡng nội mô Fuchs bị bỏ sót chẩn đoán hoặc chẩn đoán nhầm với viêm giác mạc, viêm màng bồ đào dẫn đến các điều trị sai lầm. Với mong muốn tìm hiểu rõ hơn về bệnh, chúng tôi tiến hành đề tài này với mục tiêu nhận xét đặc điểm lâm sàng, cận lâm sàng của bệnh nhân loạn dưỡng nội mô Fuchs.

\section{II. ĐỐI TƯỢNG VÀ PHƯƠNG PHÁP NGHIÊN CỨU}

Nghiên cứu mô tả cắt ngang trên 40 mắt của 23 bệnh nhân trong 15 gia đình được chẩn đoán loạn dưỡng nội mô Fuchs đến khám tại Khoa Giác mạc, Bệnh viện Mắt Trung ương từ tháng $8 / 2020$ đến tháng $7 / 2021$.

Tiêu chuẩn lựa chọn:

- Tất cả những bệnh nhân được chẩn đoán xác định là loạn dưỡng nội mô Fuchs.

- Tổn thương loạn dưỡng không kèm theo những tổn thương khác của giác mạc.

\section{Tiêu chuẩn loại trừ:}

- Những bệnh nhân loạn dưỡng nội mô Fuchs đã ghép giác mạc điều trị ở cả 2 mắt.

- Bệnh nhân từ chối tham gia nghiên cứu.

Quy trình nghiên cứu:

- Hỏi bệnh: Tuổi, giới, tiền sử gia đình, thời gian phát hiện bệnh, lý do khám bệnh, các triệu chứng cơ năng của bệnh.

- Khám chức năng: Đo thị lực bằng bảng Snellen và đo nhãn áp bằng nhã̉n áp kế Icare.

- Khám trên sinh hiển vi đèn khe: quan sát và phân tích tổn thương trên giác mạc về hình dạng, vị trí tổn thương. Khám và đánh giá tình trạng các thành phần khác của nhãn câu như tình trang tiền phòng, mống mắt, thể thuỷ tinh...

- Cận lâm sàng: chụp tế bào nội mô và đo độ dày giác trung tâm mạc bằng máy chụp nội mổ NIDEK.

- Mời các thành viên trong gia đình bệnh nhân đến khám sàng lọc gồm: bố mẹ, anh chị em ruột và con cháu.

\section{KẾT QUẢ VÀ BÀN LUẬN \\ 3.1. Đặc điểm bệnh nhân}

3.1.1. Tuổi và giới. Tuổi trung bình của 23 bệnh nhân tại thời điểm khám là $59,5 \pm 14,8$ tuổi. Bệnh nhân nhiều tuổi nhất là 83 tuổi và thấp nhất là 22 tuổi. Có 13 bệnh nhân nữ và 10 bệnh nhân nam. Tuy số lượng bệnh nhân nữ nhiều hơn nam nhưng sự khác biệt về giới không có ý 
nghĩa thống kê ( $p>0.05)$.

3.1.2. Số lượng bệnh nhân trong mỗi gia đình

Bảng 1. Số lượng bệnh nhân trong mối gia đinh

\begin{tabular}{|c|c|c|c|c|}
\hline $\begin{array}{c}\text { Số bệnh nhân } \\
\text { trong một gia } \\
\text { đình }\end{array}$ & $\mathbf{1}$ & $\mathbf{2}$ & $\mathbf{3}$ & $\mathbf{4}$ \\
\hline Số gia đình & $\begin{array}{c}10 \\
(66,7 \%)\end{array}$ & $\begin{array}{c}3 \\
(20 \%)\end{array}$ & $\begin{array}{c}1 \\
(6,7 \%)\end{array}$ & $\begin{array}{c}1 \\
(6,7 \%)\end{array}$ \\
\hline
\end{tabular}

Chỉ có 1 gia đình phát hiện được 3 bệnh nhân và 1 gia đình có 4 bênh nhân bị bênh. Còn lai đa số chỉ phát hiện được 1 bệnh nhần trong mỗi gia đình (10 gia đình, chiếm $66,7 \%$ ).

Theo y văn, loạn dưỡng nội mô Fuchs có đặc tính di truyền khá phức tạp và không đồng nhất với phần lớn các trường hợp không rõ đặc điểm di truyền, đồng thời do đặc điểm của bệnh thường xuất hiện muộn sau 40 tuổi hoặc muộn hơn ở 50 đến 60 tuổi và giai đoạn đầu bênh không biểu hiện triệu chứng cơ năng làm bệnh nhân và người nhà chủ quan đến khám muộn và hiếm có phả hệ đầy đủ. ${ }^{5}$

\section{2. Đặc điểm lâm sàng}

3.2.1. Tuổi phát hiện bệnh. Tuổi phát hiện bệnh là thời điểm bệnh nhẩn được chẩn đoán xác định loạn dương nội mô Fuchs. Tuổi phát hiện bênh trung bình trong nghiên cứu của chúng tôi là $58,0 \pm 14,6$ tuổi, muộn nhất là 83 tuổi, sớm nhất là 22 tuổi. Theo y văn hình thái loạn dương nội mô Fuchs xuất hiện muộn thường biểu hiện sau 40 tuổi, triệu chứng thường rõ ràng sau 60 tuổi. Độ tuổi trung bình trong nghiên cứu của chúng tổi lớn hơn so với nghiên cứu của Lê Xuân Cung năm 1999 (trung bình là 39 tuổi, tuổi phát hiện muộn nhất là 69, sớm nhất là 19 tuổi). ${ }^{6}$ Hầu hết các bệnh nhân được phát hiện bệnh khi tuổi đã cao do ở giai đoạn đầu, các tổn thương tinh tế và không có triệu chứng cơ năng nên thường chỉ được phát hiện tình cờ khi thăm khám mắt hoặc qua khám sàng lọc các thành viên của gia đình có người bị bệnh. Đến giai đoạn sau, khi khởi phát triệu chứng cơ năng nhìn mờ do phù nhu mô, bệnh nhân thường chủ quan nhìn mờ do tuổi tác nên không đi khám cho đến khi thị lực giảm nhiều, kích thích, chảy nước mắt do vỡ bọng biểu mô. Đồng thời nhiều bệnh nhân bị chẩn đoán nhầm phù giác mạc do loạn dưỡng nội mô Fuchs với viêm giác mạc, viêm màng bô đào và được điều trị một thời gian dài trước khi được phát hiện bệnh, dẫn tới chẩn đoán bệnh muộn. Trong thời gian tiến hành nghiên cứu chúng tôi đã phát hiện 10 bệnh nhân mới. 13 bệnh nhân còn lại đã được phát hiện bệnh trước đó và đến khám lại theo hẹn. 10 bệnh nhân được phát hiện mới có độ tuổi trung bình là $52,0 \pm 17,7$ tuổi, trong đó có 4 bệnh nhân đã đi khám nhiều lần trước đó và được chẩn đoán mắc các bệnh lý khác. Cá biệt trong nghiên cứu có 1 bệnh nhân được phát hiện bệnh ở 22 tuổi khi tình cờ đi khám theo dõi tật khúc xạ. Sau khi tiến hành khám sàng lọc, chúng tôi phát hiện thêm 3 thành viên trong gia đình mắc bệnh đều có độ tuổi trên 40 . Chúng tôi nhận định đây là hình thái loạn dưỡng nội mô Fuchs xuất hiện sớm nhưng do chưa biểu hiện triệu chứng cờ năng nên các thành viên trong gia đình được phát hiện bệnh muộn.

3.2.2. Thị lức. Thị lực là triệu chứng chức năng quan trọng gián tiếp nói lên mức độ nặng của bệnh. Tại thời điểm khám, có $6 / 23$ bệnh nhân đã được phẫu thuật ghép giác mạc 1 mắt nên tổng số mắt trong nghiên cứu là 40 mắt. Chúng tôi ghi nhận thị lực trung bình tại thời điểm khám của 40 mắt là 0,8 logMAR (tương đương 20/125 Snellen). Mức độ thị lực được thể hiện trong bảng 2 .

Bảng 2. Thị lực tại thời điểm khám

\begin{tabular}{|c|c|c|c|c|c|}
\hline $\begin{array}{l}\text { Thị } \\
\text { lực }\end{array}$ & $\begin{array}{c}<20 / \\
400\end{array}$ & $\begin{array}{l}20 / 400- \\
<20 / 200\end{array}$ & $\begin{array}{l}20 / 200- \\
<20 / 60\end{array}$ & $\begin{array}{c}\geq 20 / \\
60\end{array}$ & Tổng \\
\hline mắt & $\begin{array}{c}4 \\
(10,0 \%)\end{array}$ & $\begin{array}{c}7 \\
(17,5 \%)\end{array}$ & $\begin{array}{c}18 \\
(45,0 \%)\end{array}$ & $\begin{array}{c}11 \\
(27,5 \%)\end{array}$ & 40 \\
\hline
\end{tabular}

Đa số bệnh nhân có mức thị lực 20/20020/60 (18 mắt, chiếm tỉ lệ 45,0\%). Số mắt được phát hiện khi thị lực còn tốt $\geq 20 / 60$ chiếm $27,5 \%$. Có $27,5 \%$ số mắt có thị lực dưới mức 20/200. Đa số bệnh nhân thường đến khám khi bệnh đã ở giai đoạn muộn, giác mạc phù, có bọng biểu mô nên thị lực thường bị ảnh hưởng. Ngoài ra, do tuổi phát hiện bệnh muộn nên ngoài tổn thương loạn dưỡng tại giác mạc, bệnh nhân còn kèm theo đục thể thuỷ tinh do tuổi, cũng là một yếu tố làm giảm thị lực.

3.2.3. Nhãn áp. Trong nghiên cứu của chúng tôi $100 \%$ số mắt có giá trị nhãn áp trong mức bình thường. Mối liên quan giữa glôcôm góc mở và loạn dưỡng nội mô Fuchs hiện vẫn chưa rõ ràng và vẫn còn nhiều quan điểm trái ngược nhau. Theo Magover và cộng sự, không có mối liên quan giữa glôcôm góc mở và bệnh loạn dưỡng nội mô Fuchs, đồng thời Robert và cộng sự cũng cho rằng không có sự suy giảm dòng thuỷ dịch thoát ra khỏi tiền phòng để gây nên tình trạng tăng nhãn áp. Tuy nhiên Buxton và cộng sự lại nhận thấy sự lưu thông dòng thủy dịch qua vùng bè trên mắt bệnh nhân loạn dưỡng nội mô Fuchs giảm so với bình thường. Nghiên cứu kết luận rằng sự hoạt động của 
mạng lưới vùng bè có thể tham gia vào quá trình bệnh. ${ }^{5}$

3.2.4. Triệu chứng cơ năng. Nhìn mờ và kích thích mắt từng đợt (đỏ mắt, cộm chói, chảy nước mắt) là triệu chứng cơ năng chính của bệnh loạn dưỡng nội mô giác mạc Fuchs và thường là nguyên nhân khiến bệnh nhân đi khám bệnh. Trong nghiên cứu, cứu có 4 bệnh nhân được chẩn đoán bệnh khi chưa có triệu chứng cơ năng bao gồm 1 bệnh nhân đi khám tật khúc xạ định kỳ và 4 bệnh nhân là người nhà người bệnh đi khám sàng lọc. 19 bệnh nhân còn lại (chiếm 82,6\%) đều đi khám vì có triệu chứng cớ năng như nhìn mờ và/hoặc triệu chứng kích thích mắt từng đợt điển hình. Xét trong tổng số 23 bệnh nhân của nghiên cứu, có $91,3 \%$ bệnh nhân có triệu chứng nhìn mờ và $69,6 \%$ bểnh nhân có triệu chứng kích thích mắt do hầu hết bệnh nhân chỉ đi khám khi có các triệu chứng cơ nằng. Thời gian xuất hiện chứng cơ năng của các bệnh nhân dao động từ vài ngày đến nhiều năm cho đến khi được chẩn đoán xác định bệnh.

3.2.5. Đặc điểm tổn thương loạn dưỡng trên giác mạc. Guttae là đặc điểm tổn thương quan trọng để chẩn đoán hình thái loạn dưỡng nội mô Fuchs. Trong số 40 mắt của nghiên cứu, chúng tôi thấy có 25 mắt có giác mạc còn trong, quan sát trên sinh hiển vi đèn khe thấy 16 mắt có hình ảnh các guttae tập trung chủ yếu ở trung tâm mặt sau giác mạc với số lượng nhiêu hoặc ít, có 9 trong số 25 mắt có guttae lan ra tới vùng ngoại vi. 15 mắt có tình trạng giác mạc phù, có bọng biểu mô. Trong số 15 mắt bị phù giác mạc, có 8 mắt còn quan sát được hình ảnh guttae ở mặt sau giác mạc vùng trung tâm, cạnh trung tâm; 5 mắt giác mạc phù nhiều, không quan sát được phía mặt sau giác mạc và 2 mắt giác mạc đục, sẹo xơ ở trung tâm giác mạc phía trước, không quan sát được các tổ chức phía sau. Đối với những mắt ở giai đoạn muộn, giác mạc đã có sẹo xơ không quan sát được guttae thì việc khám mắt còn lại và phát hiện guttae là cơ sở để đưa ra chẩn đoán xác định.

Các tổn thương ghi nhận trên giác mạc ở các giai đoạn tương tự như mô tả trong y văn. Kết quả này tương tự với kết quả nghiên cứu của Lê Xuân Cung và Elhalis. ${ }^{5,} 6$ Giai đoạn đầu, bệnh nhân chưa có triệu chứng cơ năng, các guttae thường xuất hiện ở trung tâm và lan về phía ngoại vi. ở giai đoạn sau, giác mạc phù tăng dần, các bọng biểu mô xuất hiện và vỡ ra gây trợt giác mạc. Ở giai đoạn cuối, giác mạc trở nên đục và có sẹo xơ do tình trạng phù mãn tính.

3.3. Kết quả chụp tế bào nội mô. Đặc điểm tế bào nội mô và độ dày giác mạc là hai yếu tố quan trọng trong chẩn đoán, theo dõi cũng như đánh giá mức độ nặng của bệnh loạn dưỡng nội mô Fuchs. Chụp nội mô bẳng máy sinh hiển vi phản gương cho phép đánh giá các chỉ số về mật độ, kích thước, hình dạng tế bào nội mô, đồng thời có thể quan sát được hình ảnh guttae - một dấu hiệu quan trọng để chẩn đoán bệnh. ở người trưởng thành, lớp nội mô có mật độ tế bào khoảng 3500 tế bào/mm², số lượng tế bào giảm dần theo tuổi. Các tế bào nội mô không có khả năng phân chia nên khi bị tổn thương, các tế bào xung quanh sẽ giãn to và tăng hoạt động để bù lại. Khi mật độ tế bào dưới 300-500 tế bào $/ \mathrm{mm}^{2}$, lớp nội mô sẽ mất bù làm cho giác mạc bị ngấm nước và trở nên phù. ${ }^{6}$ Trong số 25 mắt giác mạc còn trong và được chụp tế bào nội mô, chỉ có 9 mắt hiển thị được kêt quả đếm tế bào nội mô. Điều này có thể do giác mạc đã có tình trạng phù kín đáo nhưng chưa quan sát được khi khám bằng sinh hiển vi. ${ }^{7}$ Mật độ tế bào nội mô trung bình của 9 mắt này là $2310 \pm 515$ tế bào/mm². Ở những bệnh nhân có số lượng tế bào nội mô giảm nhiều, đo độ dày giác mạc trung tâm là phương pháp đánh giá tốt nhất chức năng của các tế bào nội mô còn lại. ${ }^{3}$ Theo phân loại của Pateras and Koufala, chiêu dày giác mạc bình thường từ 540 đến $560 \mu \mathrm{m}$, giác mạc dày khi chiều dày trên $565 \mu \mathrm{m}$ và giác mạc rất dày nếu chiều dày trên $600 \mu \mathrm{m}^{8}{ }^{8}$ Trong nghiên cứu của chúng tôi, có 27 mắt (chiếm $67,5 \%)$ có chiều dày giác mạc ở mức dày và rất dày, 13 mắt (chiếm $33,5 \%$ ) có chiều dày giác mạc bình thường. Sự khác biệt có ý nghĩa thống kê với $p<0,05$. Độ dày giác mạc trung bình là $593,8 \pm 67,9 \mu \mathrm{m}$. Kết quả này tương tự với kết quả nghiên cứu của Malandain và Kopplin. ${ }^{4,7}$

\section{KẾT LUẬN}

Loạn dưỡng nội mô giác mạc Fuchs là bệnh lý đăc trưng bởi tình trạng mất dần tế bào nội mô, dày màng Descemet do lắng đọng chất nền ngoại bào dưới dạng guttae. Bệnh thường được tình cờ phát hiện khi thăm khám mắt hoặc phát hiện ở giai đoạn muộn khi xuất hiện triệu chứng cở năng do phù giác mạc gây ra. Chụp tế bào nội mô và đo độ dày giác mạc là hai xét nghiệm cận lâm sàng quan trọng trong chẩn đoán và theo dõi bệnh.

\section{TÀI LIẸU THAM KHẢO}

1. Eghrari AO, Riazuddin SA, Gottsch JD. Fuchs Corneal Dystrophy. Prog Mol Biol Transl Sci. 2015;134:79-97.

doi:10.1016/bs.pmbts.2015.04.005 
2. Matthaei M, Hribek A, Clahsen $T$, Bachmann B, Cursiefen C, Jun AS. Fuchs Endothelial Corneal Dystrophy: Clinical, Genetic, Pathophysiologic, and Therapeutic Aspects. Annu Rev Vis Sci. Sep 15 2019;5:151-175. doi:10.1146/annurev-vision-091718-014852

3. Greene JB, Mian SI. Cataract surgery in patients with corneal disease. Curr Opin Ophthalmol. Jan 2013;24(1):9-14 doi:10.1097/ICU.0b013e32835aeec4

4. Malandain E, Gueudry J, Boutillier G, Muraine M. [Outcomes of cataract surgery in patients with Fuchs endothelial corneal dystrophy]. J Fr Ophtalmol. Oct 2021;44(8):1180-1189. Chirurgie de cataracte seule chez le patient porteur d'une dystrophie endotheliale de Fuchs. doi:10.1016/j.jfo.2020.09.033

5. Elhalis $\mathbf{H}$, Azizi B, Jurkunas UV. Fuchs endothelial corneal dystrophy. Ocul Surf. Oct 2010; 8 (4):173-84. doi:10.1016/s1542-0124(12)70232-x

6. Lề Xuân Cung. Nhân xét đăc điểm lâm sàng và bệnh lý giải phâuu của bệnh loạn dưỡng giác mạc di truyền - gia đình. Luận văn tốt nghiêpp bác sĩ nội trú bệnh viện. Trường đại hoc Y Hà Nội; 1999.

7. Kopplin Lj, Przepyszny K, Schmotzer B, et al. Relationship of Fuchs endothelial corneal dystrophy severity to central corneal thickness. Arch Ophthalmol. Apr 2012;130(4):433-9. doi:10.1001/archopthalmol.2011.1626 10.1001/archophthalmol.2011.1626

8. Pateras E, Koufala C. Comparison between OrbscanIIz, Pentacam, Ultrasound Pachymetry (Tomey SP-100) at Different Stages of Keratoconus. Ophthalmology Research An International Journal. 07/16 2020;13:7-33. doi:10.9734/OR/2020/v13i230163

\section{GIÁ TRI CHẨN ĐOÁN CỦA PHIM CộNG HƯỞNG TỪ ĐỐI VỚI TỔN THƯƠNG SỤN KHỚP GỐI DO THOÁI HOÁ}

\section{TÓM TẮT}

Mục tiêu: phân tích giá trị chẩn của phim công hưởng từ đối với tổn thương sụn khớp gối do thoái hoá, dưa trên tiêu chuẩn vàng là nội soi khớp. Pháp nghiên cứu: nghiên cứu trển 76 bệnh nhân được chẩn đoán thoái hoá khớp gối dưa trên Xquang thường quy, theo tiêu chuẩn của Kell-gren-Lawrence, được phâuu thuật nội soi khớp gối. Tât cả đều đước chụp cộng hưởng từ (MRI) trước mổ. Mức độ tổn thương sụn khớp trên MRI được phân loại theo Vallotton. Tổn thương trong mổ nội soi khớp đước phân độ theo Outer Bridge. Kết quả: Độ nhạy, độ đặc hiệu, giá trị dự đoán dương tính, giá trị dự đoán âm tính và độ chính xác lần lượt là $69,7 \%, 85,8 \%, 80,9 \%$, $79,7 \%$ và $82,6 \%$. Kết luân: Hình ảnh $\mathrm{CHT}$ cho thấy độ đặc hiệu, các giá trị chẩn đoán dương tính và âm tính, và độ chính xác cao hơn so với chụp $X$ quang (theo các số liệu nghiên cứu trước đó)

Tư khoá: Thoái hoá khớp gối, Cộng hưởng từ, độ đặc hiệu, độ chính xác.

\section{SUMMARY \\ DIAGNOSTIC VALUE OF MAGNETIC RESONANCE \\ IMAGES IN PATIENTS WITH ARTHROSCOPIC OSTEOARTHRITIS OF THE KNEE}

Objectives: The aim of this study is to analyze the diagnostic value of magnetic resonance images (MRI) in osteoarthritic knees when using arthroscopic

${ }^{1}$ Đai Hoc Y Hà Nôi

${ }^{2}$ Bệnh viện HN Việt Đức

Chiu trách nhiêm chính: Dương Đình Toàn

Email: duongdinhtoan@hmu.edu.com

Ngày nhận bài: 8.9.2021

Ngày phản biện khoa học: 26.10.2021

Ngày duyệt bài: 10.11.2021

\section{Dương Đình Toàn ${ }^{1,2}$}

ndings as the "gold standard" to compare with. Method: A total of 76 patients were studied because of chronic pain in 1 of their knees. Radiographs were classified according to Kell- gren-Lawrence scale. Magnetic resonance images were classified according to Vallotton, and arthroscopic ndings according to Outer- bridge criteria. Results: Sensitivity, specificity, positive predictive value, negative predictive value, and accuracy were, respectively $69,7 \%, 85,8 \%$, $80,9 \%, 79,7 \%$, and $82,6 \%$ for MRI. Conclusion: Magnetic resonance images presented higher specificity, positive and negative predictive values, and accuracy than weight-bearing radiographs for knee osteoarthritis (according to other research)

Key words: radiography, osteoarthriti, bone spurs

\section{I. ĐĂT VẤN ĐỀ}

Cộng hưởng từ (MRI) là một phương tiên chẩn đoán có giá trị đối với bệnh thoái hóa khớp gối (THKG). Mức độ tổn thương thoái hóa sụn có thể được đo bằng hê thống phân loai Vallotton trên MRI [1]. Theo các nghiên cứu khác, độ nhạy của MRI chỉ đat $60 \%$ đối với những tổn thương sụn mâm chầy, đặc biệt ở mức độ thoái hoá nhẹ trong, trong khi độ đặc hiệu cao hơn 90\% [2]. Đối với những trường hợp thoái hoá nhe, độ nhay có thể từ $0 \%$ đến $86 \%$, đô đặc hiệu là $48 \%$ đến $95 \%$. Trong khi thoái hoá nặng, độ nhay có thể lên đến $98 \%$ đến $100 \%$ [3]. MRI cũng được coi là một công cư tốt hơn để đo lường sự tiến triển của thoái hoá. Giá tri chẩn đoán của MRI đối với chẩn đoán thoái hóa khớp gối còn phụ thuộc vào sức mạnh từ tính, nghĩa là MRI 3.0T kết quả chẩn đoán sẽ tốt hơn so với 